\title{
Prevalence and infection risk factors of bovine Eimeria in China: a systematic review and meta-analysis
}

\author{
Dong-Li Li ${ }^{1,2, a}$, Qing-Long Gong ${ }^{2, a}$, Gui-Yang Ge ${ }^{2}$, Qi Wang ${ }^{2}$, Chen-Yan Sheng ${ }^{2}$, Bao-Yi Ma ${ }^{2}, Z_{i}-Y_{a n g}$ Chen $^{2}$, \\ Yang Yang ${ }^{2}$, Jian-Ming $\mathrm{Li}^{1}$, Kun $\mathrm{Shi}^{1}$, Xue Leng, ${ }^{1, *}$, and Rui $\mathrm{Du}^{3, *}$ \\ ${ }^{1}$ College of Chinese Medicine Materials, Jilin Agricultural University, Changchun, Jilin Province 130118, PR China \\ 2 College of Animal Science and Technology, Jilin Agricultural University, Changchun, Jilin Province 130118, PR China \\ ${ }^{3}$ Laboratory of Production and Product Application of Sika Deer of Jilin Province, Key Laboratory of Animal Production, Product \\ Quality and Security, Ministry of Education, Jilin Agricultural University, Changchun, Jilin Province 130118, PR China
}

Received 10 October 2020, Accepted 25 June 2021, Published online 10 August 2021

\begin{abstract}
Eimeria spp. cause the disease coccidiosis, which results in chronic wasting of livestock and can lead to the death of the animal. The disease, common worldwide, has caused huge economic losses to the cattle industry in particular. This is the first systematic review and meta-analysis of the prevalence of bovine Eimeria in China. Our search of five databases including PubMed, ScienceDirect, China National Knowledge Infrastructure (CNKI), Chongqing VIP, and Wan Fang for articles published up to February 29, 2020 on the prevalence of Eimeria in cattle in mainland China yielded 46 articles, in which the prevalence of cattle ranged from $4.6 \%$ to $87.5 \%$. The rate of bovine Eimeria infection has been decreasing year by year, from $57.9 \%$ before 2000 to $25.0 \%$ after 2015 , but it is still high. We also analyzed the region, sampling years, detection methods, feeding model, seasons, and species of bovine Eimeria. We recommend that prevention strategies should focus on strengthening detection of Eimeria in calves in the intensive farming model.
\end{abstract}

Key words: Eimeria, Cattle, Mainland China, Prevalence, Meta-analysis.

\begin{abstract}
Résumé - Prévalence et facteurs de risque des infections des bovins par Eimeria en Chine : revue systématique et méta-analyse. Les espèces d'Eimeria provoquent la coccidiose, une maladie qui entraîne l'émaciation chronique du bétail et peut entraîner la mort de l'animal. La maladie, répandue dans le monde entier, a causé d'énormes pertes économiques à l'industrie bovine en particulier. Ceci est la première revue systématique et méta-analyse de la prévalence des Eimeria des bovins en Chine. Notre recherche dans cinq bases de données, dont PubMed, ScienceDirect, China National Knowledge Infrastructure (CNKI), Chongqing VIP et Wan Fang, pour des articles publiés jusqu'au 29 février 2020, sur la prévalence des Eimeria chez les bovins en Chine continentale, a donné 46 articles, dans lesquels la prévalence chez les bovins variait de 4,6\% à 87,5\%. Le taux d'infection des bovins par Eimeria a diminué d'année en année, passant de 57,9 \% avant 2000 à 25,0 \% après 2015, mais il est toujours élevé. Nous avons également analysé la région, les années d'échantillonnage, les méthodes de détection, le modèle d'alimentation, les saisons et les espèces d'Eimeria de bovins. Nous recommandons que les stratégies de prévention se concentrent sur le renforcement de la détection des Eimeria chez les veaux dans les élevages intensifs.
\end{abstract}

\section{Introduction}

Eimeriosis is caused by protozoa of the phylum Apicomplexa, family Eimeriidae and genus Eimeria, one of the most common parasitoses in cattle throughout the world [9]. Eimeria live in the intestinal cells of infected cattle [5]. The biological cycles of Eimeria are complex; the infectious form of Eimeria (sporulated oocysts) spreads rapidly over soil,

\footnotetext{
*Corresponding authors: lengxue_79@163. com;

durui197101@sina.com

${ }^{\text {a }}$ These authors contributed equally to this work
}

vegetation, or water, and it can survive in these environments for several months [7]. A few Eimeria spp. can cause clinical symptoms, such as diarrhea and weight loss. [29]. The disease occurs seasonally. Eimeria oocysts develop faster in a humid environment, and it is easy for cattle to be infected when the feed composition changes suddenly, the animals are already suffering from infectious disease, or other factors have caused decreased resistance [76]. Eimeria can infect various breeds of cattle. Infection is more common in calves less than one year old, and adult cattle often play the role of carrier. Generally, cattle will be infected with at least two species of Eimeria at the same time, and as many as eight species have been detected in a single 
sample [93]. In about $70 \%$ of calves that are infected with Eimeria, there are two or more species of the parasite [68]. The disease is endemic worldwide. Affected cattle will produce poorly, thereby causing serious economic losses in the cattle industry, for example, exceeding an estimated \$3.8 million annually in Canada [67]. Therefore, prevention of eimeriosis is more important than cure, which can reduce subclinical production losses and reduce the risk of environmental pollution [36].

A study of detection of Eimeria oocysts in Chinese dairy farms has shown that 39 of 43 dairy farms had Eimeria infection, the average prevalence was $90.7 \%$, and the prevalence of samples in each region ranged from $24.2 \%$ to $37.2 \%$ [42]. However, there has been no overall systematic estimate of the prevalence of bovine Eimeria. In 2017, Sibhat et al. [71] conducted a quantitative review of bovine tuberculosis in Ethiopia by studying 56 qualified research results. The results showed that pooled prevalence of bovine tuberculosis in Ethiopia is about $5.8 \%$, and it proved that intensive cattle husbandry was associated with increased prevalence. The results of the study provided favorable data for the prevention and control of Ethiopian bovine tuberculosis. In 2018, Ran et al. [66] analyzed the occurrence of Bovine viral diarrhea virus (BVDV) seroprevalence in dairy cattle in China by analyzing 41 eligible research results published from March 2003 to March 2018. The results showed that the pooled prevalence of BVDV in dairy cattle in China was approximate 53\%. This research was conducive to prevention of BVDV infection in China. Therefore, to understand factors affecting the prevalence of bovine Eimeria in China and help reduce the economic loss caused by Eimeria, we conducted the first review and metaanalysis of the prevalence of bovine Eimeria in this country.

\section{Materials and methods}

\section{Search strategy and selection criteria}

In our systematic review and meta-analysis, as of February 29, 2020, we used Chinese and English to search systematically in five databases: PubMed, ScienceDirect, China National Knowledge Infrastructure (CNKI), Chongqing VIP, and Wanfang. In ScienceDirect, we used "Eimeriidae", "cattle", and "China" as keywords. In PubMed, first we used MeSH Terms to search for "Eimeriida", the Entry terms obtained are "Eimeriidas" and "Eimeriidae", and the subject words and free words are connected by "OR". The retrieved search formula is "("Eimeriida"[Mesh] OR Eimeriidas OR Eimeriidae)". In the same way, we search for "Cattle"[Mesh] and "China"[Mesh] in turn, and the retrieval formulas obtained are: ("Cattle"[Mesh] OR Bos indicus OR Zebu OR Zebus OR Bos taurus OR Cow, Domestic OR Cows, Domestic OR Domestic Cow OR Domestic Cows OR Bos grunniens OR Yak OR Yaks); "China"[Mesh]) OR People's Republic of China) OR Mainland China) OR Manchuria) OR Sinkiang) OR Inner Mongolia). The Boolean operator "AND" is used to connect the three search queries. The final search formula is "("Eimeriida"[Mesh]) OR Eimeriidas) OR Eimeriidae)" AND ("Cattle"[Mesh] OR Bos indicus OR Zebu OR Zebus OR Bos taurus OR Cow, Domestic OR Cows, Domestic OR Domestic Cow OR Domestic Cows
OR Bos grunniens OR Yak OR Yaks) AND (“China”[Mesh] OR People's Republic of China OR Mainland China OR Manchuria OR Sinkiang OR Inner Mongolia)". In the VIP Chinese Journal Databases, the search strategy set was "title or keywords: coccidiosis AND cattle". In CNKI and Wanfang Data, the search strategy was "theme: coccidiosis AND cattle". In the three Chinese databases, all the retrieval processes included fuzzy searches and synonym expansion. We neither contacted the authors of original studies for additional information nor identified related unpublished data. Endnote X9 was used to edit the articles retrieved.

After removing duplicates, we selected each article based on the title and abstract. Then we applied the following inclusion criteria: (1) the purpose of the study was to check the prevalence of Eimeria in cattle; (2) the study provided the total number of cattle tested and prevalence; (3) each sample was from one type of cattle (not a mixed sample); (4) the study sample size was greater than 30; and (5) the study design was cross-sectional. Articles that did not meet these criteria were removed.

\section{Data extraction and quality assessment}

Four authors (CYS, BYM, ZYC, and YY) extracted data with standardized data collection forms to identify eligible studies [80]. Any disagreement between the authors or uncertainty about a study was further evaluated by an additional author (QLG). From all the collected studies, we extracted the following information: first author, publication year, sampling year, geographical region of study, location of study, age, Eimeria species, species of cattle, detection methods, feeding model, total number of cattle, and number of eimeriosis seropositive cattle. The data collection form is presented in Table 1. The quality of eligible publications was estimated based on criteria derived from the Grading of Recommendations Assessment, Development and Evaluation method [28]. In short, 1 point was awarded for each of the following items: random sampling, the sampling was random, the detection method and sampling method were each described in detail, and the sampling time was clear. A score of 4 or 5 points was deemed high quality; 2 or 3 points, moderate quality; and 0 or 1 , low quality.

\section{Statistical analysis}

The pooled prevalence of bovine Eimeria based on numerous studies was calculated by meta-analysis. A high chance of heterogeneity in the included studies was presupposed; by using $\mathrm{R}$ software for analysis, the results were linear distributions with $W$-values greater than 0.9 . Thus, a random-effects model was employed to calculate and prepare forest plots using Stata 12 software (Stata Corp., College Station, TX, USA) [62]. Heterogeneity was anticipated, and statistical methods with $I^{2}$ and Cochran's $Q$ (represented as $\chi^{2}$ and $p$-value) statistics were used to assess the variations. The potential sources of heterogeneity were further investigated by subgroup analysis and meta-regression analysis. The investigated factors 
Table 1. Studies included in the analysis.

\begin{tabular}{|c|c|c|c|c|c|c|}
\hline Study ID & $\begin{array}{l}\text { Sampling } \\
\text { time }\end{array}$ & Province & Detection method & $\begin{array}{c}\text { Positive } \\
\text { samples/total } \\
\text { samples }(\text { Coccidia })\end{array}$ & $\begin{array}{l}\text { Quality } \\
\text { score }\end{array}$ & $\begin{array}{c}\text { Quality } \\
\text { level }\end{array}$ \\
\hline
\end{tabular}

Central China
Liu [50]
Zhao et al. [91]
Shi et al. [70]
Zhang et al. [97]
Chen et al. [12]
Zhang et al. [98]
Dong et al. [18]
Zhan and Zhao [90]
Eastern China
Ye [85]
Liu et al. [48]
Zhao et al. [94]
Lu and Zhang [54]
Li et al. [44]
Dong et al. [18]

Dong et al. [19]

Northern China

Nie et al. [64]

Wang et al. [79]

Sun [74]

\section{$\mathrm{Xu}$ et al. [83]}

Cao [8]

Dong et al. [18]

Henan
Henan
Henan
Henan
Henan
Henan
Henan
Hunan

UN

$2014.6-2014.12$
$2005.1-12$

1990.03-1991.10

$\mathrm{UN}$

2010

2010.11-2011.03

2015-2017

2007.7-2009.8

2003.03-2003.04

2009.01-2009.11

2015.11-2016.11

2010

\section{Zhejiang \\ Shandong \\ Shanghai \\ Anhui \\ Anhui \\ Shanghai \\ Shandong \\ Jiangsu}

Inner
Mongolia
Shanxi
Inner
Mongolia
Beijing
Hebei
Beijing
Inner
Mongolia

Northwestern China

Wang [78]

Cong [13]

Feng et al. [24]

Zhan [89]

Zhang et al. [96]

\section{Ma [55]}

Ma et al. [56]

Ni et al. [63]

Li [46]

E L [20]

Guo et al. [26]

Zhai et al [88]

Jiang [34]

Zhang et al. [95]

Zhao [92]

Dong et al. [32]

$\begin{array}{cc}\text { UN } & \text { Qinghai } \\ \text { 2011.7-2012.8 } & \text { Shaanxi } \\ \text { UN } & \text { Shaanxi } \\ \text { 1989.3-1989.5 } & \text { Qinghai } \\ 2016.6-2016.8 & \text { Xinjiang } \\ \text { 2017.1-2017.2 } & \\ \text { 2018.1-2018.3 } & \\ \text { 2012.9-2014.12 } & \text { Xinjiang } \\ \text { UN } & \text { Xinjiang } \\ \text { 2014.09 } & \text { Gansu } \\ \text { UN } & \text { Qinghai } \\ \text { UN } & \text { Qinghai } \\ \text { 2014.05-2015.10 } & \text { Qinghai } \\ \text { UN } & \text { Shaanxi } \\ \text { 2013.05-2013.06 } & \text { Xinjiang } \\ \text { 2016.08-2016.10 } & \text { Xinjiang } \\ \text { UN } & \text { Shaanxi } \\ \text { 2010.11-2011.01 } & \text { Qinghai }\end{array}$

Comprehensive approach
Comprehensive approach
Saturated saline water floating
Saturated saline water precipitation
Comprehensive approach
Saturated saline water precipitation
Saturated saline water precipitation
Comprehensive approach

Others

Saturated saline water floating

Saturated saline water precipitation

Saturated saline water floating

Saturated saline water floating

Saturated saline water precipitation

Others

Comprehensive approach

Saturated saline water floating

Comprehensive approach

Saturated saline water floating

Saturated saline water floating

Saturated saline water precipitation

samples (Coccidia)

Southern China

Liang et al. [47]
Wei et al. [81]
Wu et al. [82]
Mi et al. [58]

2016.4
$2013-2014$
2014.1
UN

Guangdong
Guangxi
Guangxi
Guangxi

Saturated saline water floating

Comprehensive approach

Saturated saline water floating

Saturated saline water floating

Saturated saline water floating

Saturated saline water floating Comprehensive approach

Saturated saline water floating

Saturated saline water floating

Saturated saline water floating

Saturated sucrose floating

Saturated saline water floating

Saturated sucrose floating

Saturated sucrose floating

Saturated saline water floating

$$
\text { Others }
$$

$83 / 460$
$134 / 218$
$570 / 1520$
$110 / 503$
$136 / 466$
$66 / 223$
$37 / 73$
$28 / 32$

High

Middle

Middle

Middle

High

Middle

High

Middle

$56 / 215$

$35 / 763$

$269 / 718$

$233 / 280$

$540 / 814$

$88 / 169$

$295 / 626$

Middle

Middle

High

High

High

High

High

$159 / 1009$

$136 / 1200$

$76 / 265$

$1953 / 3419$

$107 / 1020$

$89 / 183$

Middle

Middle

High

High

High

High

$\begin{array}{ccc}268 / 460 & 2 & \text { Middle } \\ 65 / 177 & 3 & \text { Middle } \\ 25 / 49 & 3 & \text { Middle } \\ 37 / 48 & 5 & \text { High } \\ 172 / 524 & 3 & \text { Middle }\end{array}$

$48 / 128$

$75 / 211$

$108 / 234$

$38 / 50$

$156 / 500$

$310 / 587$

$22 / 48$

166/718

$487 / 1391$

22/48

$113 / 324$
Middle

Middle

High

Middle

Middle

High

Middle

High

High

High

High

\begin{tabular}{cccc} 
Comprehensive approach & $358 / 1440$ & 3 & Middle \\
Comprehensive approach & $697 / 2952$ & 4 & High \\
Comprehensive approach & $128 / 109$ & 2 & Middle \\
Saturated saline water floating & $50 / 100$ & 2 & Middle \\
\hline
\end{tabular}


Table 1. (Continued)

\begin{tabular}{|c|c|c|c|c|c|c|}
\hline Study ID & $\begin{array}{l}\text { Sampling } \\
\text { time }\end{array}$ & Province & Detection method & $\begin{array}{c}\text { Positive } \\
\text { samples/total } \\
\text { samples (Coccidia) }\end{array}$ & $\begin{array}{l}\text { Quality } \\
\text { score }\end{array}$ & $\begin{array}{l}\text { Quality } \\
\text { level }\end{array}$ \\
\hline \multicolumn{7}{|l|}{ Southwestern China } \\
\hline Yu et al. [87] & UN & Sichuan & Others & $10 / 50$ & 2 & Middle \\
\hline Zhao [14] & 1990 & Guizhou & Saturated saline water floating & $748 / 1202$ & 3 & Middle \\
\hline $\operatorname{Li}[43]$ & $2017.8-2017.9$ & Yuannan & Comprehensive approach & $15 / 44$ & 5 & High \\
\hline Jiang and Zhu [33] & $1986.9-1986.12$ & Sichuan & Others & $46 / 122$ & 2 & Middle \\
\hline Shen et al. [69] & 2018.1 .20 & Sichuan & Comprehensive approach & $13 / 90$ & 5 & High \\
\hline He et al. [20] & $2007.05-2008.10$ & Sichuan & Saturated saline water floating & $150 / 500$ & 3 & Middle \\
\hline Dong et al. [18] & 2010 & Sichuan & $\begin{array}{l}\text { Saturated saline water } \\
\text { precipitation }\end{array}$ & $3 / 10$ & 5 & High \\
\hline Liu [49] & 2011.10-2011.11 & Yunnan & Saturated saline water floating & $37 / 118$ & 2 & Middle \\
\hline
\end{tabular}

$\mathrm{UN}^{*}$ : unclear.

ND*: No data.

Region*: Central China: Henan; Eastern China: Zhejiang, Shandong, Shanghai, Anhu, Hunan Northern China: Inner Mongolia, Shanxi, Beijing, Hebei; Northwestern China: Qinghai, Shaanxi, Xinjiang, Gansu; Southern China: Guangdong, Guangxi; Southwestern China: Sichuan, Guizhou, Yunnan.

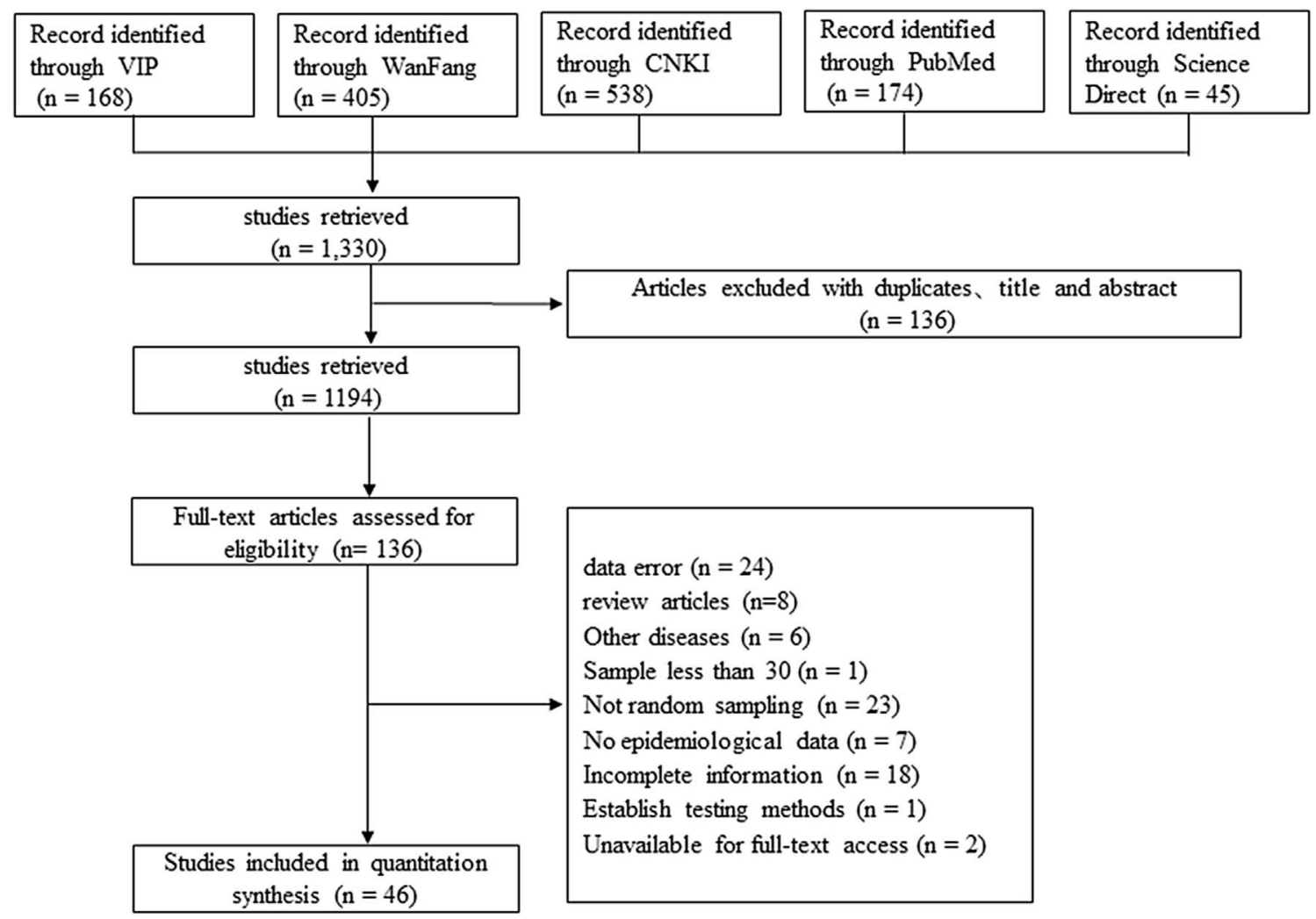

Figure 1. Screening process for eligible articles.

comprised the geographical region, the sampled year (comparison of studies published before 2000, between 2000 and 2015, and the period since 2015), the age of cattle (comparison of calves before weaning, calves after weaning, growing cattle with finishing cattle), the species of Eimeria, season (comparison of spring and summer with autumn and winter), feeding model (comparison of extensive with intensive), the cattle species and detection method (comparison of saturated saline flotation method, saturated saline precipitation method, saturated sucrose flotation method, comprehensive approach, and other method). We performed a sensitivity analysis for the included studies to verify the stability of the results. Publication bias of the studies included in this meta-analysis was statistically examined with Egger's test and trim and fill analysis using Stata software (version 12.0). The meta-analysis was performed according to the PRISMA guidelines [60]. 


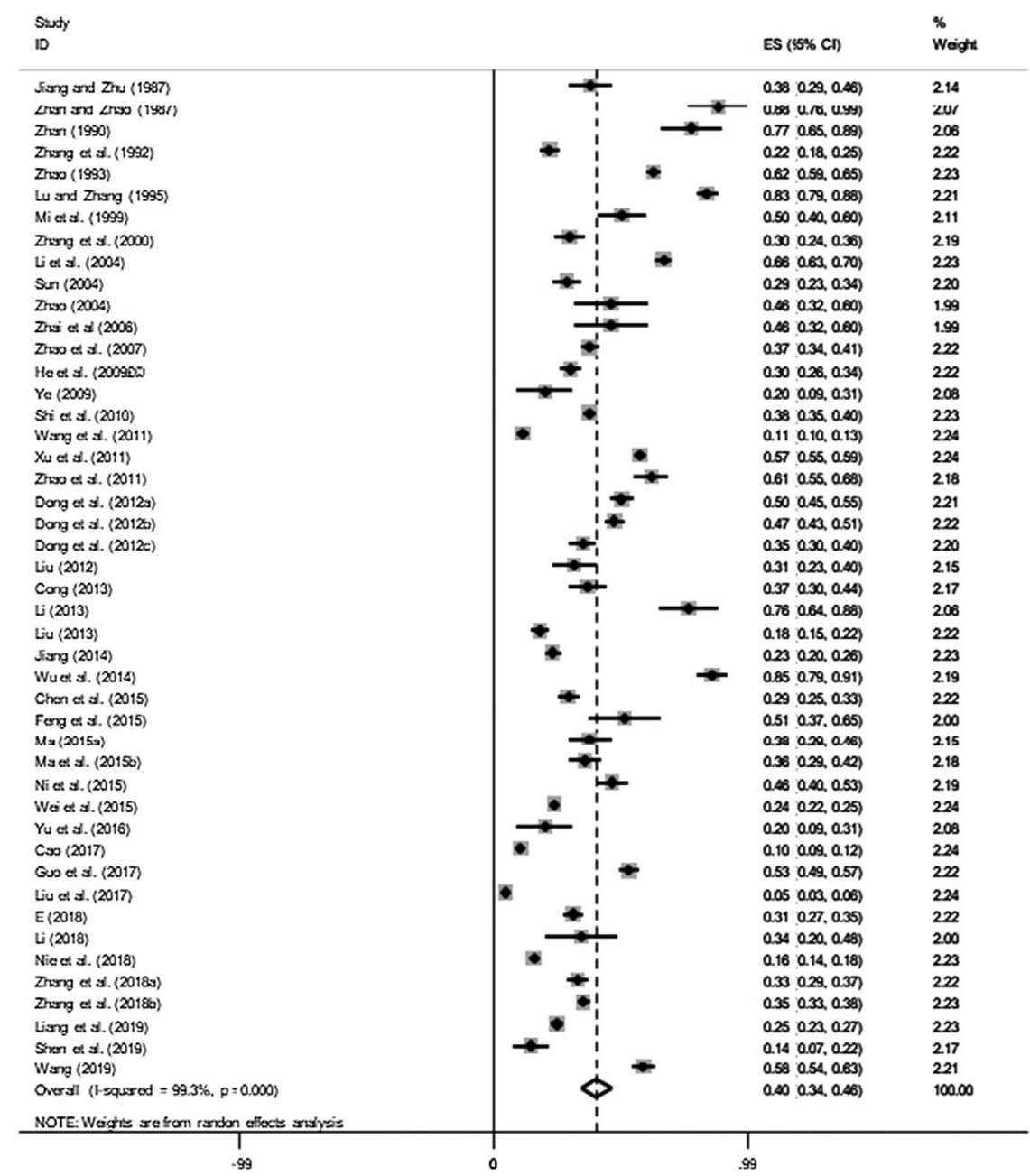

Figure 2. Forest plot of bovine Eimeria prevalence among studies conducted in China.

\section{Results}

\section{Included studies}

In this study, we searched 1330 articles in five databases, and 46 articles were selected for inclusion in our systematic review and meta-analysis (Fig. 1). We evaluated the quality of each article by region, detection method, sampling year, age of cattle, type of cattle, breeding method and season. Of the 46 articles, 34 were scored as high quality ( 4 or 5 points), 10 were categorized as medium quality ( 2 or 3 points), and the remaining two papers were classified as low quality ( 0 or 1 point) (Table 1).

\section{Publication bias}

The extent of publication bias in the selected studies was measured and demonstrated by a forest map and funnel plot (Figs. 2 and 3). These data clearly indicated that there were enough publications included to appropriately assess the prevalence of bovine Eimeria. The funnel plot did not visually indicate whether there was publication bias, so we conducted Egger's test and trim and fill analysis to further evaluate the presence of publication bias. Egger's test result showed
$P=0.011$ (Table S1), and the result of the trim and fill analysis demonstrated that the publication bias disappeared after the addition of two related studies, implying that the studies we included had publication bias or small-study effect bias (Fig. S2, Tables S2 and S3).

\section{Sensitivity analysis}

A sensitivity analysis was also conducted (Fig. S1), in which one study at a time was removed and the others analyzed to estimate whether the results could have been alected markedly by a single study. The results showed that after excluding a certain study, the results of the reorganization analysis are basically consistent with the previous results, so we believe that the results of our meta-analysis are relatively stable and reliable.

\section{Related factors of bovine Eimeria infection in cattle in China}

The purpose of our research was to assess the distribution of bovine Eimeria in China. The sample distribution we included in the study covered 19 provinces in six regions. Only the northeastern region has no relevant studies. According to our analysis, no statistically significant difference between regions 


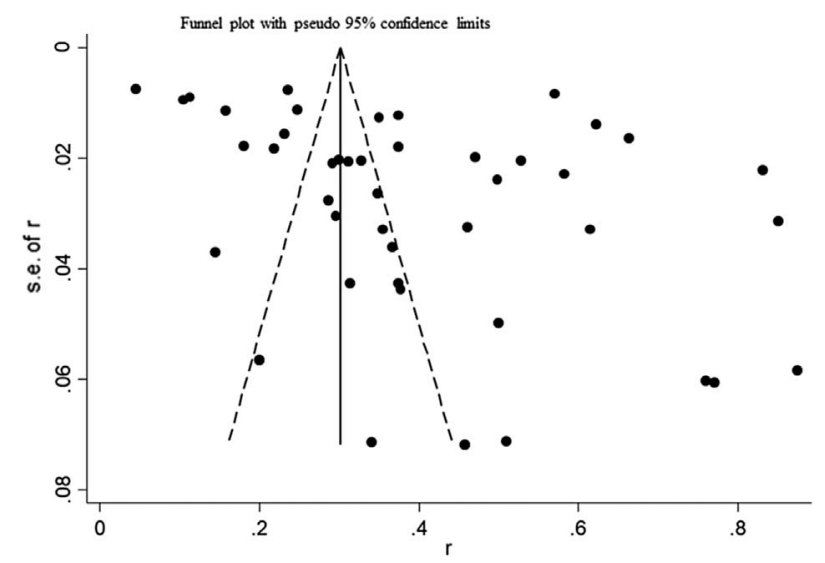

Figure 3. Funnel plot with pseudo $95 \%$ confidence limits intervals for the examination o publication bias.

was found (Table 2). Of all the provinces, Hunan had the highest prevalence $(87.5 \%, 95 \%$ CI [76.0-99.0]), which may, however, be attributable to small-study bias (Table 3). Data for the included studies were collected between 1986 and 2018; there was a statistically significant difference between the intervals before 2000, between 2000 and 2015, and after 2015, and the prevalence for the first interval was highest, $57.9 \%$ (95\% CI [39.4-76.4]). There was no statistically significant difference among the different types of cattle, namely: buffalo, dairy cow, scalper, yak, and all others. In our study, calves after weaning (2-12 months old) had the highest prevalence at $37.1 \%$ (95\% CI [33.6-40.5]). Our study used two sampling seasons: autumn and winter, and spring and summer, among which autumn and winter prevalence was $44.3 \%$ (95\% CI [13.4-75.3]) and the spring and summer prevalence was $32.9 \%$ (95\% CI [22.9-42.9]). The prevalence of the saturated saline flotation method in the articles we included was $47.7 \%$ (95\% CI [35.6-59.8]), higher than that of the saturated saline precipitation method, saturated sucrose water flotation method, comprehensive approach and other methods. The feeding methods in our study include two kinds of breeding methods, extensive and intensive. The prevalence in extensive breeding was $53.9 \%$ (95\% CI [40.9-67.0]) and that in intensive breeding, 35.2\% (95\% CI [22.4-48.0]) (Table 2). Pooled prevalence for each of the 17 species of Eimeria included, among which E. bareillyi had the highest prevalence, is shown in Table 4.

\section{Discussion and conclusion}

Bovine eimeriosis is a parasitic gastrointestinal disease caused by Eimeria spp., which is the fifth most important economically and has a major impact on the global cattle industry [41]. To date, 20 species of bovine Eimeria have been reported in the world. Oocysts in the environment can be transmitted through the fecal-oral route. Cattle are susceptible to being infected with eimeriosis if they consume contaminated feed, water, or forage [6]. In calves infected with Eimeria, fever, anorexia, abdominal pain, dehydration, weakness, and even death may occur. Symptoms in breeding cattle are mainly subclinical, but they can still act as a vector for the protozoa [16]. Because Eimeria cause serious economic losses to the cattle industry, we constructed the first meta-analysis to assess the prevalence of bovine eimeriosis in China and potential infection risk factors. The total prevalence of Eimeria in Chinese cattle was $40.0 \%$, which was lower than the prevalence in Mexico (60.2\%), in North America in cattle (91.7\%), and buffalo $(81.5 \%)$ in three regions of Italy $[2,61]$. By contrast, it was higher than the prevalence in the Gwangju area of Korea $(10.0 \%)$ and in Western Kenya $(32.8 \%)$ [38, 57].

In the regions we studied, the prevalence in northern China was much lower than those in southern China. This may be caused by the following reasons: first of all, Eimeria species oocysts can survive within $-30{ }^{\circ} \mathrm{C}$, and the survival time at -5 to $8{ }^{\circ} \mathrm{C}$ is much longer than $-30{ }^{\circ} \mathrm{C}$ [75] The climate in China is very complicated, and the monthly average temperature difference between the north and south in winter can reach about $30{ }^{\circ} \mathrm{C}$ [45], so a suitable temperature in the south will be more suitable for the survival of Eimeria. Secondly, because a dry climate is not suitable for the survival of Eimeria oocysts, infection with bovine Eimeria is more serious in the humid southerly regions than in the slightly dry north [17]. In addition, animal husbandry in southern China has developed rapidly, the number of cattle raised is large, and the eimeriosis prevalence will be higher, which is consistent with our research results. However, the difference was not significant $(p>0.05)$, probably because the number of articles in each region we included varies greatly. It is worth noting that we were not able to assess the prevalence of bovine Eimeria in the northeast because no studies on bovine Eimeria in the northeast were included (Jilin, Liaoning, and Heilongjiang). Importantly, the high prevalence in Hunan Province might be because there was only one article in the province and the total number of samples was only 32 . Therefore, in order to more accurately reflect the true prevalence of Eimeria in cattle in China, it is recommended to further expand the scope of investigation of Eimeria in cattle, increase the sample size of the investigation, and reduce small-study effects bias.

In meta-analysis of rates, the detection method is usually a source of heterogeneity. All the studies we included used traditional fecal testing methods to detect Eimeria. The fecal flotation test is the most commonly used technique in clinical laboratory, medical and veterinary medicine for separation of oocysts and eggs. Compared with noncentrifugal flotation methods, centrifugal flotation methods are obviously faster and more efficient [21]. The saturated saline water floating method and saturated sucrose floating method have the highest prevalence in our research, which is consistent with the above conclusions. Research has developed assays that can distinguish Eimeria species by polymerase chain reaction (PCR) targeting the species-specific ITS-1 region. Considering sensitivity and reliability, PCR appears to be better than conventional oocyst stool examination and can identify important species of bovine Eimeria [35]. Compared with the four flotation options of Brine, Saturated sugar solution, Zinc sulphate solution and Sodium chloride Solution, the Mini-FLOTAC technique using salt/sugar solution is more sensitive and convenient, especially in mixed infections. In addition, this method is suitable for laboratories with limited resources [4]. Traditional fecal testing 
Table 2. Pooled prevalence of Eimeria in cattle in mainland China.

\begin{tabular}{|c|c|c|c|c|c|c|c|c|c|c|}
\hline & & \multirow[t]{2}{*}{$\begin{array}{l}\text { No. } \\
\text { studies }\end{array}$} & \multirow[t]{2}{*}{$\begin{array}{l}\text { No. } \\
\text { tested }\end{array}$} & \multirow[t]{2}{*}{$\begin{array}{c}\text { No. } \\
\text { positive }\end{array}$} & \multirow[t]{2}{*}{$\%\left(95 \% \mathrm{CI}^{*}\right)$} & \multicolumn{3}{|c|}{ Heterogeneity } & \multicolumn{2}{|c|}{$\begin{array}{c}\text { Univariate } \\
\text { meta-regression }\end{array}$} \\
\hline & & & & & & $v^{2}$ & $p$-value & $I^{2}(\%)$ & $p$-value & $\begin{array}{l}\text { Coefficient } \\
(95 \% \mathrm{CI})^{*}\end{array}$ \\
\hline \multirow[t]{7}{*}{ Region* } & & & & & & & & & 0.118 & -0.135 \\
\hline & Central China & 8 & 3495 & 1164 & $41.1 \%(30.7-51.4)$ & 293.04 & 0.000 & $97.6 \%$ & & $(-0.307$ to 0.036$)$ \\
\hline & Eastern China & 7 & 3585 & 1516 & $45.2 \%(20.0-70.5)$ & 2247.00 & 0.000 & $99.7 \%$ & & \\
\hline & Northern China & 6 & 7096 & 2520 & $28.6 \%(9.6-47.6)$ & 1986.08 & 0.000 & $99.7 \%$ & & \\
\hline & Northwestern China & 16 & 5497 & 2112 & $44.2 \%(37.9-50.5)$ & 336.36 & 0.000 & $95.5 \%$ & & \\
\hline & Southern China & 4 & 4620 & 1214 & $45.5 \%(28.2-62.9)$ & 385.91 & 0.000 & $99.2 \%$ & & \\
\hline & Southwestern China & 8 & 2136 & 1022 & $32.7 \%(17.2-48.2)$ & 308.60 & 0.000 & $97.7 \%$ & & \\
\hline \multirow[t]{6}{*}{$\begin{array}{l}\text { Detection } \\
\text { methds }\end{array}$} & & & & & & & & & 0.102 & $\begin{array}{c}0.106 \\
(-0.022 \text { to } 0.233)\end{array}$ \\
\hline & Saturated saline water precipitation & 4 & 1879 & 662 & $34.7 \%(22.8-46.6)$ & 92.93 & 0.000 & $96.8 \%$ & & \\
\hline & Saturated saline water floating & 19 & 11,955 & 5006 & $47.7 \%(35.6-59.8)$ & 4874.66 & 0.000 & $99.6 \%$ & & \\
\hline & Saturated sucrose floating & 5 & 3680 & 1403 & $40.3 \%(28.5-52.1)$ & 228.82 & 0.000 & $98.3 \%$ & & \\
\hline & Comprehensive approach & 13 & 7492 & 1948 & $37.5 \%(29.4-45.6)$ & 721.09 & 0.000 & $98.3 \%$ & & \\
\hline & Others & 5 & 1337 & 520 & $33.7 \%(24.1-43.2)$ & 48.38 & 0.000 & $91.7 \%$ & & \\
\hline \multirow[t]{4}{*}{$\begin{array}{c}\text { Sampling } \\
\text { years }\end{array}$} & & & & & & & & & 0.015 & $\begin{array}{c}0.233 \\
(0.049 \text { to } 0.417)\end{array}$ \\
\hline & Before 2000 & 5 & 1875 & 1130 & $57.9 \%(39.4-76.4)$ & 239.45 & 0.000 & $98.3 \%$ & & \\
\hline & 2000-2015 & 21 & 15,956 & 5707 & $37.2 \%(28.6-45.9)$ & 3431.15 & 0.000 & $99.4 \%$ & & \\
\hline & After 2015 & 6 & 4509 & 1152 & $25.0 \%(15.1-34.8)$ & 288.45 & 0.000 & $98.3 \%$ & & \\
\hline \multirow[t]{5}{*}{ Cattle ages* } & & & & & & & & & 0.003 & -0.153 \\
\hline & Calves before weaning & 6 & 1024 & 284 & $28.9 \%(22.4-35.4)$ & 24.77 & 0.000 & $79.8 \%$ & & $(-0.253$ to -0.053$)$ \\
\hline & Calves after weaning & 11 & 3235 & 1383 & $39.9 \%(34.0-45.7)$ & 233.51 & 0.000 & $90.2 \%$ & & \\
\hline & Growing cattle & 14 & 2490 & 1008 & $38.9 \%(23.6-54.1)$ & 1286.59 & 0.000 & $98.9 \%$ & & \\
\hline & Finishing cattle & 19 & 4735 & 1475 & $22.7 \%(14.1-31.2)$ & 1360.35 & 0.000 & $98.5 \%$ & & \\
\hline \multirow[t]{6}{*}{$\begin{array}{l}\text { Species } \\
\text { of cattle }\end{array}$} & & & & & & & & & & \\
\hline & Buffalo & 6 & 1907 & 913 & $57.4 \%(37.7-77.0)$ & 351.65 & 0.000 & $98.6 \%$ & 0.052 & $\begin{array}{c}0.168 \\
(-0.001 \text { to } 0.337)\end{array}$ \\
\hline & Dairy cow & 25 & 17,011 & 6154 & $38.5 \%(30.9-46.1)$ & 3060.64 & 0.000 & $99.2 \%$ & & \\
\hline & Others & 3 & 919 & 371 & $43.6 \%(26.0-61.1)$ & 55.56 & 0.000 & $96.4 \%$ & & \\
\hline & Scalper & 2 & 995 & 617 & $42.5 \%(-0.9$ to 85.8$)$ & 56.82 & 0.000 & $98.2 \%$ & & \\
\hline & Yak & 7 & 2543 & 1081 & $45.3 \%(34.8-55.8)$ & 178.88 & 0.000 & $96.6 \%$ & & \\
\hline \multirow[t]{3}{*}{$\begin{array}{l}\text { Feeding } \\
\text { model }\end{array}$} & & & & & & & & & 0.115 & $\begin{array}{c}0.193 \\
(-0.054 \text { to } 0.441)\end{array}$ \\
\hline & Extensive & 5 & 776 & 388 & $53.9 \%(40.9-67.0)$ & 46.48 & 0.000 & $91.4 \%$ & & \\
\hline & Intensive & 10 & 5691 & 1540 & $35.2 \%(22.4-48.0)$ & 1796.63 & 0.000 & $99.5 \%$ & & \\
\hline \multirow[t]{3}{*}{ Season* } & & & & & & & & & 0.501 & $\begin{array}{c}0.108 \\
(-0.240 \text { to } 0.456)\end{array}$ \\
\hline & Autumn and winter & 4 & 570 & 267 & $44.3 \%(13.4-75.3)$ & 237.14 & 0.000 & $98.7 \%$ & & \\
\hline & Spring and summer & 7 & 3081 & 841 & $32.9 \%(22.9-42.9)$ & 234.26 & 0.000 & $97.4 \%$ & & \\
\hline \multirow[t]{4}{*}{$\begin{array}{l}\text { Quality } \\
\text { level* }\end{array}$} & & & & & & & & & 0.228 & $\begin{array}{c}0.087 \\
(-0.056 \text { to } 0.229)\end{array}$ \\
\hline & Middle & 10 & 2692 & 911 & $47.0 \%(30.8-63.1)$ & 2828.64 & 0.000 & $99.1 \%$ & & \\
\hline & High & 34 & 23,137 & 8431 & $38.2 \%(31.2-45.1)$ & 2771.60 & 0.000 & $909.3 \%$ & & \\
\hline & Low & 2 & 600 & 206 & $40.0 \%(21.7-58.4)$ & 12.07 & 0.000 & $91.7 \%$ & & \\
\hline Total & & 46 & 26,264 & 9502 & $40.0 \%(34.0-46.0)$ & 6087.31 & 0.000 & $99.3 \%$ & & \\
\hline
\end{tabular}

CI*: Confidence interval.

Region*: Central China: Henan; Eastern China: Zhejiang, Shandong, Shanghai, Anhu, Hunan Northern China: Inner Mongolia, Shanxi, Beijing, Hebei; Northeastern China: Qinghai, Shaanxi, Xinjiang, Gansu; Southern China: Guangdong, Guangxi; Southwestern China: Sichuan, Guizhou, Yunnan.

Season*: Spring and summer: March through August. Autumn and winter: September through February.

Cattle ages*: Calves before weaning ( 0 months old to 2 months old), Calves after weaning ( 2 months old to 12 months old), Growing cattle (12 months old to 24 months old), Finishing cattle ( $>24$ months old).

Quality level *: Low: 0 or 1 points; Middle: 2 or 3 points; High: 4 or 5 points. 
Table 3. Estimated pooled seroprevalence of Eimeria by provincial regions in China.

\begin{tabular}{|c|c|c|c|c|c|c|}
\hline Province & No. studies & Region & No. tested & No. positive & $\%$ Prevalence & $\%(95 \% \mathrm{CI})$ \\
\hline Anhui & 2 & Eastern China & 1094 & 773 & $74.7 \%$ & $58.2-91.2$ \\
\hline Beijing & 1 & Northern China & 3419 & 1953 & $57.1 \%$ & $55.5-58.8$ \\
\hline Gansu & 1 & Northeastern China & 234 & 108 & $46.2 \%$ & $39.8-52.5$ \\
\hline Guangdong & 1 & Southern China & 1440 & 358 & $24.9 \%$ & $22.6-27.1$ \\
\hline Guangxi & 3 & Southern China & 3180 & 856 & $52.9 \%$ & $9.8-95.9$ \\
\hline Guizhou & 1 & Southwestern China & 12,062 & 748 & $62.2 \%$ & $59.5-65.0$ \\
\hline Hebei & 1 & Northern China & 1020 & 107 & $10.5 \%$ & $8.6-12.4$ \\
\hline Henan & 6 & Central China & 3390 & 1099 & $32.7 \%$ & $22.9-42.6$ \\
\hline Hunan & 1 & Central China & 32 & 28 & $87.5 \%$ & $76.0-99.0$ \\
\hline Inner Mongolia & 2 & Northern China & 1274 & 235 & $22.0 \%$ & $9.3-34.6$ \\
\hline Qinghai & 6 & Northeastern China & 1969 & 922 & $54.2 \%$ & $41.6-66.8$ \\
\hline Shaanxi & 4 & Northeastern China & 322 & 134 & $42.8 \%$ & $35.9-49.7$ \\
\hline Shandong & 1 & Eastern China & 763 & 35 & $4.6 \%$ & $3.1-6.1$ \\
\hline Shanghai & 2 & Eastern China & 1344 & 564 & $42.3 \%$ & $32.8-51.7$ \\
\hline Shanxi & 1 & Northern China & 1200 & 136 & $11.3 \%$ & $9.5-13.1$ \\
\hline Sichuan & 4 & Southwestern China & 762 & 219 & $25.7 \%$ & $16.1-35.3$ \\
\hline Xinjiang & 5 & Northeastern China & 2972 & 948 & $35.0 \%$ & $32.5-37.5$ \\
\hline Yunan & 2 & Southwestern China & 162 & 52 & $32.1 \%$ & $24.9-39.3$ \\
\hline Zhejiang & 1 & Eastern China & 215 & 56 & $26.0 \%$ & $20.2-31.9$ \\
\hline Total & & & 25,994 & 9331 & $39.9 \%$ & $33.9-46.0$ \\
\hline
\end{tabular}

Table 4. Pooled prevalence of different Eimeria species in mainland China.

\begin{tabular}{|c|c|c|c|c|}
\hline Species of Coccidia & No. studies & No. tested & No. positive & $\%\left(95 \% \mathrm{CI}^{*}\right)$ \\
\hline E. auburnensis & 13 & 5834 & 672 & $11.0 \%(6.6-15.4)$ \\
\hline E. canadensis & 12 & 5351 & 594 & $11.8 \%(7.4-16.1)$ \\
\hline E. ellips & 14 & 7021 & 1154 & $13.4 \%(7.8-18.9)$ \\
\hline E. alabamensis & 10 & 5169 & 379 & $8.5 \%(5.1-12.0)$ \\
\hline E. bareillyi & 1 & 50 & 30 & $60.0 \%(46.4-73.6)$ \\
\hline E. bovis & 13 & 6421 & 1135 & $23.4 \%(16.5-30.4)$ \\
\hline E. brasiliensis & 6 & 3280 & 179 & $7.6 \%(4.1-11.1)$ \\
\hline E. bukidnonensis & 4 & 1645 & 180 & $10.3 \%(7.7-12.9)$ \\
\hline E. cylindrica & 12 & 6878 & 355 & $6.4 \%(4.3-8.5)$ \\
\hline E. kwangsiensis & 1 & 814 & 28 & $3.4 \%(2.2-4.7)$ \\
\hline E. mandela & 1 & 1520 & 85 & $5.6 \%(4.4-6.7)$ \\
\hline E. pellita & 6 & 1885 & 64 & $3.3 \%(1.1-5.5)$ \\
\hline E. subspherica & 12 & 6454 & 612 & $12.7 \%(9.1-16.4)$ \\
\hline E. wyomingensis & 7 & 4004 & 231 & $6.4 \%(2.5-10.2)$ \\
\hline E. zurnii & 15 & 7139 & 1013 & $17.4 \%(10.6-12.7)$ \\
\hline E. illinoisensis & 1 & 118 & 3 & $2.5 \%(-0.3$ to 5.3$)$ \\
\hline E. stiedai-like & 1 & 118 & 1 & $0.9 \%(-0.8$ to 2.5$)$ \\
\hline
\end{tabular}

methods are usually used to identify oocysts. The number of sporangia in the oocysts and the distribution of sporozoites are useful characteristics for distinguishing the genus of Eimeria. In addition, it can also be distinguished according to the size, shape and color of the oocysts [21], but they are usually subjective and require significant parasitological expertise and complicated solution preparation, and they are not reliable for species identification [39]. The detection methods used in the articles included in this study are all routine stool detection, which is less convenient, slower, and less accurate than the PCR method. According to the characteristics of Eimeria species that can be distinguished by PCR technology, highly pathogenic Eimeria can be detected, which provides an effective basis for the prevention and control of Eimeria. When the experimental conditions permit, we believe that the PCR method should be selected to detect bovine Eimeria.

We found that in the past 32 years, the prevalence of bovine Eimeria in China showed a significant downward trend $(p<0.05)$. At the beginning of the reform and opening up, the stock of cattle increased rapidly while little attention was paid to the prevention and control of Eimeria emmetaria, so the parasite spread quickly. This is consistent with our research results. In our study, the prevalence of bovine Eimeria showed a downward trend year by year, which may have the following reasons: first, since 2000, the Chinese government has successively promulgated policies such as the "Animal Husbandry Law" and "Animal Epidemic Prevention Law" to strengthen support for the development of animal husbandry [11]. Second, in recent years, the level of animal husbandry 
has developed, and more and more attention has been paid to the prevention and control of bovine Eimeria. Commonly used preventive drugs included monensin, amprolium, diclazuril and toltrazuril, and therapeutic drugs included furacilin [51, 65]. This measure has eased the impact of Eimeria on the cattle industry. Third, since 2012, the Chinese government has begun to pay more and more attention to environmental pollution caused by animal husbandry: for example, the 12th Five-Year Plan of National Livestock and Poultry Pollution Control issued by the Ministry of Environmental Protection (MEP) and the Ministry of Agriculture (MOA) to strengthen environmental governance [86]. In 2015, the Ministry of Agriculture proposed to implement "Regulations on the Prevention and Control of Pollution from Large-scale Livestock and Poultry Farming," combined with the pilot project of comprehensive utilization of livestock and poultry manure and other agricultural and rural wastes; strengthen guidance and services; summarize and promote efficient and applicable comprehensive treatment of manure; and provide resources to support the main points of animal husbandry work based on the utilization model (China Ministry of Agriculture 2015). In 2018, the Chinese Ministry of Agriculture proposed to create a new model for the development of animal husbandry, continue to implement county-wide projects to promote the utilization of manure resources, increase capital investment, and expand coverage (China Ministry of Agriculture 2018). The Chinese government has established a rural energy biogas system to manage rural livestock and poultry farming manure, thereby reducing pollution from farming and reducing Eimeria prevalence. Therefore, formulating corresponding prevention and control policies may play a positive role in reducing bovine Eimeria infection. The above measures have reduced the risk of bovine eimeriosis infection.

There are two main breeding methods in China's cattle industry: intensive farming model and free-range farming [30]. Intensive, large-scale, standardization is the main strategy for the development of animal husbandry [72]. The transformation of breeding mode in China's cattle industry reduces the risk of bovine Eimeria infection, which is consistent with the results of our study. Our research found that although the point estimate of the intensive farming model is lower than that of extensive, the difference is not significant, and the prevalence of Eimeria in cattle under the two farming models is greater than $35 \%$. Intensive farming is denser, and a large amount of manure may not be processed in time, leading to widespread epidemics of infectious diseases [10,84], which is also the cause of Eimeria infection in intensive farming [15]. Further tracing back to the original text, it was found that most studies on intensive farming did not mention the details of manure treatment. At present, some cattle farms in China may not pay attention to the centralized treatment of manure, which has led to uneven quality and prevalence of intensive farming [72]. The "Implementation Opinions on Fighting the Tough Battle for the Prevention and Control of Agricultural Non-point Source Pollution" issued by the Ministry of Agriculture in 2015 requires that the proportion of supporting waste treatment facilities for large-scale livestock and poultry farms (communities) be more than 75\% [77]. The "Action Plan for the Zero Growth of Chemical Fertilizer Use by 2020" issued in the same year requires the promotion of the resource utilization of livestock manure and the reduction of chemical fertilizers through organic fertilizer replacement and commitment to livestock manure treatment (Ministry of Agriculture in China, 2015). We found that in articles published after this, the prevalence of Eimeria in intensive farming showed a downward trend. We suggest further implementation of high-level intensive farming to increase the utilization of cattle industry resources, while reducing the spread of diseases such as Eimeria.

According to reports, Eimeria prevalence in cattle of all age groups varies greatly, mainly affecting calves. The prevalence of calves over 6 months old is higher than that of calves 1-6 months old, which may be related to good care and colostrum feeding, especially colostrum can improve the immunity of calves. In addition, 18-month-old cattle are also unlikely to be infected with bovine Eimeria due to their highly immunity [3, 22, 25, 37, 57] - this is consistent with our findings. The eimeriosis prevalence of calves before weaning ( $<2$ months) is significantly lower than that of calves after weaning (2-12 months), which may occur because calves acquire antibodies from breast milk [23]. The clinical manifestation of Eimeria in calves is characterized by abdominal pain, watery to hemorrhagic diarrhea, fever, and dehydration [37], which have a great impact on the development of the cattle industry. Therefore, based on the results of our research, attention should be paid to the protection of calves to avoid excessive contact between calves and worm-carrying cattle. If conditions permit, feeding calves and adult cattle separately may help prevent the infection of Eimeria in calves.

Many breeds of cattle can be infected with Eimeria. There are more than 11 common species of Eimeria in water buffalo. Among them, E. bareillyi is a unique species in buffalo [21], a host animal that is found in warm and humid environments [27], so higher prevalence of Eimeria in buffalo may be expected. In our research, the Eimeria prevalence of dairy cows is the lowest, which may be due to the high requirements for food safety and the rapid promotion of mechanization, and intelligence and information technology in dairy farming facilities [99]. The dairy farming environment in China is cleaner, which reduces the chance of Eimeria infection. In addition, in China, yak and yellow cattle are generally regarded as labor cattle, and they have wider home ranges, so they have more opportunities for contact with infectious Eimeria oocysts.

Although season is not the main factor affecting eimeriosis infection in cattle, prevalence vareies with season [73]. A study by Al-Jubory has shown that summer eimeriosis has the lowest prevalence and autumn eimeriosis has a higher prevalence [1] and this may be because the autumn temperature and humidity are more suitable for growth and reproduction. It has also been reported that the lower temperature of Eimeria oocysts in winter results in fewer spores and a lower shedding rate [59]; therefore, the prevalence of bovine eimeriosis in winter will be reduced, which is consistent with our research results. We found relatively few articles that recorded the sampling season, and we urge that these data be collected comprehensively to clarify the seasonality of Eimeria infection.

Up to eight different Eimeria species have arisen in mixed infections [53], though not all species of Eimeria are pathogenic. Eimeria zuernii and E. bovis are considered the most pathogenic [52]. Infection of calves with a large number of oocysts of E. zuernii or E. bovis may lead to severe diarrhea 
including blood, intestinal tissue, and fibrin [16]. LasprillaMantilla et al. have also proven this conclusion [40], which is consistent with our research results; however, the difference in our own analysis was not statistically significant. In our study, E. bareillyi had the highest prevalence, which may be due to the fact that the total number of samples taken in the study of $E$. bareillyi is only 50 cattle, and the total number of samples is too small, which leads to biased research results. Meanwhile, there are relatively few studies on E. kwangsiensis, E. mandela, E. illinoisensis and E. stiedai-like. The prevalence derived from our analysis should be generalized with caution because several included articles did not use random sampling.

The advantages of this research are the wide range of the research, the long time span of the research, the large sample size, and the thorough examination of potential risk factors. There were, however, several limitations to our analysis. Firstly, we identified studies related to bovine Eimeria in the selected databases by searching using several different MeSH terms; however, these searches may not have found all the relevant studies. Secondly, some of the factors included in some studies and the sample size are too small, so there may be a smallsample size bias, resulting in unstable outcomes. Finally, the research we included may not be particularly accurate because some of the samples in the included articles were not randomly sampled.

This systematic review and meta-analysis showed that bovine Eimeria occurs in most regions of China, and the prevalence has been declining year by year. The age of cattle is one of the main reasons that affects the prevalence of Eimeria. To reduce the risk of bovine Eimeria infection, farmers should pay special attention to calves, control the density in intensive breeding, keep the breeding environment clean, and strengthen precautions recommended in policy documents. At the same time, it is necessary to develop more convenient, faster, and more accurate methods to detect Eimeria.

\section{Supplementary materials}

Supplementary material is available at https://www.parasitejournal.org/10.1051/parasite/2021055/olm

Figure S1. Egger's publication bias plot.

Figure S2. Publication bias of studies by Trim ad Fill analysis.

Figure S3. Sensitive analysis.

Table S1. Egger's for publication bias.

Table S2. Trimming estimator.

Table S3. Filled meta-analysis.

Table S4. PRISMA checklist item.

Table S5. Included studies and quality scores.

\section{Financial support}

This work was funded by the Science and Technology Development Program of Jilin Province (20190304004YY).

\section{Conflict of interest}

The authors declare that they have no competing interests.

\section{References}

1. Al-Jubory QJA. 2016. Prevalence of Eimeria parasite in cattle in Al-Najaf province and its relation to risk factors: age, gender and season. Euphrates Journal of Agriculture Science, 08, 9-18.

2. Alcala-Canto Y, Figueroa-Castillo JA, Ibarra-Velarde F, VeraMontenegro Y, Cervantes-Valencia ME, Alberti-Navarro A. 2020. First database of the spatial distribution of Eimeria species of cattle, sheep and goats in Mexico. Parasitology Research, 119, 1057-1074.

3. Alemayehu A, Nuru M, Belina T, Mekibib B, Desta T, Tesfaye DJJoVM, Health A. 2013. Prevalence of bovine coccidia in Kombolcha district of South Wollo, Ethiopia. Journal of Veterinary Medicine, 05, 41-45.

4. Akande FA, Philip AM. 2020. Diagnosis of bovine gastrointestinal parasites: comparison of different techniques and different solutions. ResearchSquare, Preprint, https://doi.org/ 10.21203/rs.2.21588/v1.

5. Anjos AVD, De MEVCS, Souza MNED, Dias MA. 2011. Frequency of species of the genus Eimeria in naturally infected cattle in Southern Bahia, Northeast Brazil. Revista Brasileira de Parasitologia Veterinária, 20, 78-81.

6. Bangoura B, Bardsley KD. 2020. Ruminant Coccidiosis. Veterinary Clinics: Food Animal Practice, 36, 187-203.

7. Bueno CL, Eduardo NJO, Azeredo BTDS, Monteiro CLF, Dos SJB, Beltrán ZDM, Assis CASD, Cayeiro CB, Lino BDGA, Almeida BFDJRBDPV. 2018. Eimeria species in dairy and beef cattle of different ages in Goiás state, Brazil. Revista Brasileira de Parasitologia Veterinária, 27, 169-176.

8. Cao WB. 2017. Infection investigation and research of current situation on coccidium and cryptoridium of cattle in partial districts of Hebei province. Baoding: Hebei Agricultural University.

9. Cardim ST, Seixas M, Tabacow VBD, Taroda A, Carneiro PG, Martins TA, Barros LD, Minutti AF, Chryssafidis AL, Vidotto O, Garcia JL. 2018. Prevalence of Eimeria spp. in calves from dairy farms in northern Paraná state, Brazil. Revista Brasileira de Parasitologia Veterinária, 27, 119-123.

10. Chai HG. 2019. Occurrence characteristics and prevention and control measures of cattle disease. Chinese Journal of Animal Husbandry and Veterinary Medicine, 516, 107-107.

11. Chen C. 2011. Retrospect and prospect of my country's animal husbandry development since the new century. Agricultural Outlook, 07, 39-42.

12. Chen GY, Wang HY, Li L, Li AX, Pei SL. 2015. Investigation of intestinal parasitic infections in dairy cows and identification of the two main protozoal species and genotypes. Chinese Journal of Veterinary Medicine, 51, 47-49.

13. Cong MM. 2013. Investigation on intestinal parasites infection and identification on species of Cyclospora and cryptosp oridium from the captive wild animals in Shaanxi Province. Xianyang: Northwest A\&F University.

14. Cui YF, Tian FR, Liu YD, Li XR, Yang XQ, Zhang Q, Chen BG. 1993. Investigation and morphological observation of bovine coccidia in Yanhe County, Guizhou. Chinese Journal of Animal Infectious Diseases, 01, 46-49.

15. Das M, Deka D, Sarmah P, Islam S, Sarma S. 2015. Diversity of Eimeria spp. in dairy cattle of Guwahati, Assam, India. Veterinary World, 08, 941-945.

16. Daugschies A, Najdrowski M. 2005. Eimeriosis in cattle: current understanding. Journal of Veterinary Medicine, Series B, 52, 417-427.

17. Dejene A, Deneke Y, Ibrahim N. 2016. Prevalence and associated risk factors of calf coccidiosis in and around Asela Town, Southeast Ethiopia. Journal of Natural Sciences Research, 06, 107-111. 
18. Dong H, Cao XL, Huang B, Han HY, Zhao QP. 2012. Epidemiological survey of coccidiosis in dairy cows in some areas of China. China Dairy Cattle, 30, 29-31.

19. Dong H, Zhao QP, Han HY, Jiang LL, Zhu SH, Li T, Kong CL, Huang B. 2012. Prevalence of Coccidial infection in dairy cattle in Shanghai, China. Journal of Parasitology, 98, 963-966.

20. E L. 2018. Epidemiological investigation of coccidiosis in yak. China Animal Husbandry \& Veterinary Medicine, 34, 128.

21. El-Alfy E, Abbas I, Al-Kappany Y, Al-Araby M, Abu-Elwafa SA, Dubey JP. 2019. Prevalence of Eimeria Species in Water Buffaloes (Bubalus bubalis) from Egypt and first report of Eimeria bareillyi oocysts. Journal of Parasitology, 105, 748-754.

22. Ekawasti F, Nurcahyo W, Wardhana AH, Shibahara T, Tokoro M, Sasai K, Matsubayashi M. 2019. Molecular characterization of highly pathogenic Eimeria species among beef cattle on Java Island, Indonesia. Parasitology International, 72, 101927.

23. Faber JE, Kollmann D, Heise A, Bauer C, Failing K, Bürger HJ, Zahner H. 2002. Eimeria infections in cows in the periparturient phase and their calves: oocyst excretion and levels of specific serum and colostrum antibodies. Veterinary Parasitology, 104, 1-17.

24. Feng P, Zhang P, Qu L. 2015. Investigation on coccidia species of cows in a dairy farm in Shenmu County. Heilongiiang Animal Science and Veterinary Medicine, 62(77-79), 187.

25. Gebeyehu B, Kebede E, Kifleyohannes T, Abebe N, Kumar N. 2018. Prevalence of calf coccidiosis in Mekelle, Northern Ethiopia. Ethiopian Veterinary Journal, 22, 1-13.

26. Guo ZH, Peng M, Shen XY, Fu Y, Duo H, Li J, Luo ZQ, Qi G. 2017. Investigation on coccidia infection of yaks in different ages in some areas of Qinghai. Journal of Qinghai University, 35, 42-47.

27. Gupta A, Singh NK, Singh H, Rath SS. 2016. Assessment of risk factors associated with prevalence of coccidiosis in dairy animals of Punjab. Journal of Parasitic Diseases, 40, 1359-1364.

28. Guyatt GH, Oxman AD, Vist GE, Kunz R, Falck-Ytter Y, Alonso-Coello P, Schunemann HJJB. 2008. GRADE: an emerging consensus on rating quality of evidence and strength of recommendations. BMJ-British Medical Journal, 336, 924-926.

29. Hamid PH, Kristianingrum YP, Prastowo S. 2019. Bovine coccidiosis cases of beef and dairy cattle in Indonesia. Veterinary Parasitology: Regional Studies and Reports, 17, 100298.

30. Han XP, Hubbert B, Hubbert M, Reinhardt CD. 2016. Overview of the beef cattle industry in China: The widening deficit between demand and output in a vicious circle. Journal of Fisheries \& Livestock Production, 4, 190.

31. He AX, Jiang ZR, Ye ZM, Wang T, Yang GY, Yin DY, Jiang J. 2009. Epidemiological investigation of coccidiosis in yak. China Animal Husbandry \& Veterinary Medicine, 36, 154-156.

32. Hui D, Li C, Zhao Q, Li J, Han H, Jiang L, Zhu S, Li T, Kong C, Huang B, Cai J. 2012. Prevalence of Eimeria infection in yaks on the Qinghai-Tibet plateau of China. Journal of Parasitology, 98, 958-962.

33. Jiang XS, Zhu HQ. 1987. Investigation and Research on Coccidia of Yak. Journal of Southwest Minzu University (Natural Science Edition), 02, 26-31.

34. Jiang YH. 2014. Infection Investigation to dairy cow Coccidium, Toxoplasma gondii and Trichomonas in large-scale dairy farm in Kuitun and Shihezi. Shihezi: Shihezi University.

35. Kawahara F, Zhang G, Mingala CN, Yu T, Nunoya T. 2010. Genetic analysis and development of species-specific PCR assays based on ITS-1 region of rRNA in bovine Eimeria parasites. Veterinary Parasitology, 174, 49-57.

36. Keeton STN, Navarre CB. 2018. Coccidiosis in large and small ruminants. Veterinary Clinics: Food Animal Practice, 34, 201-208.
37. Kim H-C, Choe C, Kim S, Chae J-S, Yu D-H, Park J, Park B-K, Choi K-S. 2018. Epidemiological survey on Eimeria spp. associated with diarrhea in pre-weaned native Korean calves. Korean Journal of Parasitology, 56, 619-623.

38. Koh B-R-D, Kim H-J, Oh A, Jung B-R, Park J-S, Lee J-G, Na H-M, Kim Y-H. 2019. Prevalence of enteropathogens in the feces from diarrheic Korean native cattle in Gwangju area, Korea. Korean Journal of Veterinary Service, 42, 93-112.

39. Lalonde LF, Gajadhar AA. 2011. Detection and differentiation of coccidian oocysts by real-time PCR and melting curve analysis. Journal of Parasitology, 97, 725-730.

40. Lasprilla-Mantilla MI, Wagner V, Pena J, Frechette A, Thivierge K, Dufour S, Fernandez-Prada C. 2019. Effects of recycled manure solids bedding on the spread of gastrointestinal parasites in the environment of dairies and milk. Journal of Dairy Science, 102, 11308-11316.

41. Lee S-H, Kim H-Y, Lee H, Kim JW, Lee Y-R, Chae MJ, Oh S-I, Kim JH, Rhee MH, Kwon O-D. 2018. Eimeria species in cattle with diarrhoea in the Republic of Korea regarding age, season and nature of diarrhoea. Veterinary Record, 183, 504-504.

42. Li H, Guo YJ, Liu C, Pan BL, Du QJ. 2016. Epidemiological investigation of cow coccidiosis in some areas of my country. Chinese Journal of Animal Science, 52, 35-38.

43. Li JH. 2018. Investigation on the infection of parasites in the digestive tract of dairy cows in a certain area of Kunming. Shanghai Journal of Animal Husbandry and Veterinary Medicine, 63, 14-15.

44. Li PY, Li JN, Hu GP, Hao SP, Xu JH. 2004. Investigation on coccidia infection and distribution of dairy cows in Anhui Province. China Dairy Cattle, 22, 19-20.

45. Li QP, Ding YH. 2004. Multi-year simulation and performance verification of regional climate models on East Asian monsoon and precipitation in China. Acta Meteorologica Sinica, 62, 140-153.

46. Li SS. 2013. Investigation on Coccidiosis of yak calves in Luanhaizi Grassland in Huangcheng. Chinese Qinghai Journal of Animal and Veterinary Sciences, 43, 34-34.

47. Liang N, Chang YK, Cui CH, Li DF, Zheng SJ, Chen YC, Pang G, Suo X. 2019. Investigation on intestinal parasite infection of dairy cows in some areas of Guangdong. Chinese Veterinary Science, 49, 1096-1103.

48. Liu CJ, Zhu LS, Liu FH, Wang HL, Wang ZC. 2017. Investigation on the epidemic areas of main cattle parasites in Luxi Region. Modern Animal Husbandry, 01, 55-56.

49. Liu CX. 2012. Coccidia species identification and natural infection rate of goats, sheep and buffalo in Kunming and Mengzi areas. Kunming: Yunnan University.

50. Liu J. 2013. Epidemiological investigation of intestinal parasites of rabbit and cattle in Henan Province and molecular characteristics of Rabbit Giardia Isolates. Zhengzhou: Henan Agricultural University.

51. Liu ZH, Zhang YZ. 2019. Diagnosis and control of bovine coccidiosis. Modern Animal Husbandry, 40, 34.

52. López-Osorio S, Silva LM, Taubert A, Chaparro-Gutiérrez JJ, Hermosilla CR. 2018. Concomitant in vitro development of Eimeria zuernii-and Eimeria bovis-macromeronts in primary host endothelial cells. Parasitology International, 67, 742-750.

53. Lopez-Osorio S, Villar D, Failing K, Taubert A, Hermosilla C, Chaparro-Gutierrez JJ. 2020. Epidemiological survey and risk factor analysis on Eimeria infections in calves and young cattle up to 1 year old in Colombia. Parasitology Research, 119, 255-266.

54. Lu G, Zhang HY. 1995. Investigation of buffalo coccidia species and infection rate in Chaohu Area, Anhui Province. Chinese Journal of Animal Infectious Diseases, 03, 44-46. 
55. Ma Q. 2015. Study on infection situation investigation of the digestive tract parasites of cattle and sheep of south mountain ranch in Urumqi. Urumqi: Xinjiang Agricultural University.

56. Ma Y, Qiao J, Meng QL, Liu TL, Li QP, Zhang JY, Chen CF. 2015. Investigation of coccidia infection in calves and identification of insect species in Northern Xinjiang. China Dairy Cattle, 33, 45-48.

57. Makau DN, Gitau GK, Muchemi GK, Thomas LF, Cook EA, Wardrop NA, Fèvre EM, de Glanville WA. 2017. Environmental predictors of bovine Eimeria infection in western Kenya. Tropical Animal Health and Production, 49, 409-416.

58. Mi TG, Huang ZX, Zhang YQ. 1999. Preliminary Investigation of buffalo coccidia species in Liuzhou, Guangxi. Chinese Journal of Animal Infectious Diseases, 07, 24-25.

59. Mitchell ESE, Smith RP, Ellis-Iversen J. 2012. Husbandry risk factors associated with subclinical coccidiosis in young cattle. Veterinary Journal, 193, 119-123.

60. Moher D, Shamseer L, Clarke M, Ghersi D, Liberati A, Petticrew M, Shekelle P, Stewart LA. 2015. Preferred reporting items for systematic review and meta-analysis protocols (PRISMA-P) 2015 statement. Systematic Reviews, 04, 1-9.

61. Morgoglione ME, Bosco A, Maurelli MP, Alves LC, Saralli G, Bruni G, Cringoli G, Rinaldi L. 2020. A 10-year surveillance of Eimeria spp. in cattle and buffaloes in a Mediterranean Area. Frontiers in Veterinary Science, 07, 410-410.

62. Ni HB, Gong QL, Zhao Q, Li XY, Zhang XX. 2020. Prevalence of Haemophilus parasuis "Glaesserella parasuis" in pigs in China: a systematic review and meta-analysis. Preventive Veterinary Medicine, 182, 105083.

63. Ni XT, Yin MY, Tan QD, Qin SY, Zhou DH, Zhu XQ, Sun XL. 2015. Epidemiological investigation and identification of coccidiosis in dairy cows in Yuzhong County. Gansu, 42, 2806-2811.

64. Nie FG, Yin XJ, Qian YH, Guo SP, Chen XJ, Xu YF, Yang XY, Wang R. 2018. Epidemiological survey of common parasites in large-scale cattle farms in parts of Inner Mongolia. Animal Husbandry and Feed Science, 39, 92-95.

65. Philippe P, Alzieu JP, Taylor MA, Dorchies Ph. 2014. Comparative efficacy of diclazuril (Vecoxan) and toltrazuril (Baycox bovis) against natural infections of Eimeria bovis and Eimeria zuernii in French calves. Veterinary Parasitology, 206, 129-137.

66. Ran XH, Chen XH, Ma LL, Wen XB, Zhai JJ, Wang WW, Tong XD, Hou GY, Ni HB. 2018. A systematic review and meta-analysis of the epidemiology of bovine viral diarrhea virus (BVDV) infection in dairy cattle in China. Acta Tropica, 190, 296-303.

67. Rehman TU, Khan MN, Sajid MS, Rao ZA, Arshad M, Iqbal Z, Iqbal A. 2011. Epidemiology of Eimeria and associated risk factors in cattle of district Toba Tek Singh, Pakistan. Indian Journal of Animal Sciences, 108, 1171-1177.

68. Sara LO, Silva LMR, Anja T, Chaparro-Gutiérrez JJ, Hermosilla CR. 2018. Concomitant in vitro development of Eimeria zuernii-and Eimeria bovis- macromeronts in primary host endothelial cells. Parasitology International, 67, 742-750.

69. Shen QY, Zhang CS, Luo ZZ, Yong K, He Q, Wang Y, Cao SZ. 2019. Investigation on parasites in fecal samples of a dairy farm in Sichuan. China Dairy Cattle, 37, 36-40.

70. Shi DM, Chen Y, Wang J. 2010. Epidemiological investigation of dairy cow coccidiosis in Henan Province. China Dairy Cattle, 28, 51-53.

71. Sibhat B, Asmare K, Demissie K, Ayelet G, Mamo G, Ameni G. 2017. Bovine tuberculosis in Ethiopia: a systematic review and meta-analysis. Preventive Veterinary Medicine, 147, 149-157.
72. Sims J, Bergström L, Bowman B, Oenema OJSU, Management. 2005. Nutrient management for intensive animal agriculture: policies and practices for sustainability. Soil Use and Management, 21, 141-151.

73. Stewart DI, Smith PR, Ellis J. 2008. Eimeria species in cattle on farms in England and Wales. Veterinary Record, 162, 482-483.

74. Sun WP. 2004. Epidemiological investigation on dairy cow coccidiosis and cryptosporidiosis in the area of Baoto. Hohhot: Inner Mongolia Agricultural University.

75. Svensson C, Uggla A, Pehrson B. 1994. Eimeria alabamensis infection as a cause of diarrhoea in calves at pasture. Veterinary Parasitology, 53, 33-43.

76. Swarnkar CP, Singh D. 2020. Prevalence of Eimeria species in sheep of arid and semi-arid Rajasthan. Veterinary Parasitology, 26, 79-85.

77. This Publication. 2015. Ministry of Agriculture: In 2020, the manure treatment facilities of farms will reach more than $75 \%$. Jiangxi Journal of Animal Husbandry \& Veterinary Medicine, $34,49$.

78. Wang QH. 2019. A comparison of coccidiosis infection between grazing yak and cattle in shed in Qinghai. Veterinary Orientation, 42, 222

79. Wang R, Ding YL, Wang ZB, Du CC, Wang JL, Liu XG, Jiao GY, Guo Y, Wang FL. 2011. Investigation and comprehensive prevention and control measures of gastrointestinal parasites in cattle and sheep in Shanxi Province. Heilongjiang Animal Science and Veterinary Medicine, 54, 114-115.

80. Wang W, Gong QL, Zeng A, Li MH, Zhao Q, Ni HB. 2021. Prevalence of Cryptosporidium in pigs in China: A systematic review and meta-analysis. Transboundary and Emerging Diseases, 68, 1400-1413.

81. Wei ZF, Tan Y, Lu YQ, Qin RF, Tao L, Li J, Chen ZX, Bi BF, Yang W. 2015. Investigation on parasite infection of buffalo and dairy cows in Guangxi. Chinese Livestock and Poultry Breeding, 11, 3-5.

82. Wu XX, Kang YQ, Yang L, Li J, Huang WY. 2014. Investigation report on gastrointestinal parasites infection in a cattle farm in Liubei District, Liuzhou City. Guangxi Journal of Animal Husbandry \& Veterinary Medicine, 30, 305-306.

83. Xu FR, Zhao JY, Pan BL, Wei HT, Zhu JJ, Liu XD, Ma ZJ, Li DL, Zhao HJ, Yu Q, Wang M. 2011. Investigation on the infection of parasites in dairy cows in Beijing area. Chinese Journal of Veterinary Medicine, 47, 9-12.

84. Xu Y, Li J, Zhang XB, Wang LQ, Xu XB, Xu L, Gong HR, Xie HY, Li FD. 2019. Data integration analysis: heavy metal pollution in China's large-scale cattle rearing and reduction potential in manure utilization. Veterinary Parasitology, 232, 308-317.

85. Ye XJ. 2009. The infection situation and countermeasures of dairy cow's parasitic diseases in Jinhua area. Contemporary Animal Husbandry, 29, 14-15.

86. Yi Q, Song K, Tao H, Ying T. 2018. Environmental status of livestock and poultry sectors in China under current transformation stage. Science of the Total Environment, 622-623, 702-709.

87. Yu SM, Ye YG, Liao DJ. 2016. Investigation report on cattle and sheep parasitic diseases in Danba County. Sichuan Animal Veterinary Sciences, 43, 20-21.

88. Zhai JJ, Yu SK, Lin Q, Zhang HF. 2006. Investigation on coccidia species of cows in a certain cattle farm in Yangling, Shaanxi. Animal Husbandry \& Veterinary Medicine, 38, 35-37.

89. Zhan SX. 1990. Investigation on coccidia species of dairy cows in Xining Area. Journal of Qinghai Animal Husbandry and Veterinary Medicine College, 007, 71-72. 
90. Zhan YT, Zhao DW. 1987. Investigation on parasites of buffalo calves in a livestock farm in Huarong. Hunan Agricultural Sciences, 17, 42.

91. Zhao JF, Qi M, Dong HJ, Li K, Ning CS, Zhang LX. 2011. Investigation on intestinal parasite infection of red cattle in Jiaxian County, Henan Province. China Animal Husbandry \& Veterinary Medicine, 38, 178-180.

92. Zhao QP. 2004. Investigation on Coccidia infection and species identification of cows in a dairy farm in Yangling. Xianyang: Northwest A\&F University.

93. Zhao QP, Han HY, Wang ZJ, Dong H, Jiang LL, Wang X, Han JF, Huang B, Yuan YM. 2007. Investigation on coccidia infection status of dairy farms in Shanghai. Animal Husbandry \& Veterinary Medicine, 39, 43-46.

94. Zhao QP, Han HY, Wang ZJ, Dong H, Jiang LL, Han JF, Wang X, Huang B, Yuan YM. 2007. Seasonal dynamics of coccidiosis infection in dairy cows in Shanghai in 2005. Chinese Veterinary Science, 37, 386-389.
95. Zhang KK, Li ZG, Zhang QY, Zhao AY, Xu CY, Jing B, Qi M. 2018. Investigation on the prevalence of coccidiosis in largescale dairy farms in Xinjiang. Animal Husbandry \& Veterinary Medicine, 50, 87-90.

96. Zhang KK, Xing JM, Xu CY, Zhao XG, Chen C, Li ZG, Zhao AY, Jing B, Qi M. 2019. Investigation on intestinal parasite infection of brown cattle in some areas of Xinjiang. Heilongjiang Animal Science and Veterinary Medicine, 62(75-77), 174.

97. Zhang L, Zhou JX, Hou AZ, Wang SR. 1992. Investigation report of bovine coccidia species and epidemiology in Henan Province. Henan Journal of Animal Husbandry and Veterinary Medicine, 13, 52-53.

98. Zhang LX, Ning CS, He QJ, Wang YB, Song TJ, Yuan Y. 2000. Epidemiological investigation and species identification of coccidiosis in dairy cows in Zhengzhou. Journal of Henan Agricultural University, 34, 88-93.

99. Zheng GS, Shi ZX, Teng GH. 2019. Research progress on equipment technology of dairy farming facilities in China. Chinese Journal of Animal Science, 55, 169-174.

Cite this article as: Li D-L, Gong Q-L, Ge G-Y, Wang Q-Y, Sheng C-Y, Ma B-Y, Chen Z-Y, Yang Y, Li J-M, Shi K, Leng X \& Du R. 2021. Prevalence and infection risk factors of bovine Eimeria in China: a systematic review and meta-analysis. Parasite $\mathbf{2 8 ,} 61$.

\section{PARASTE}

An international open-access, peer-reviewed, online journal publishing high quality papers on all aspects of human and animal parasitology

Reviews, articles and short notes may be submitted. Fields include, but are not limited to: general, medical and veterinary parasitology; morphology, including ultrastructure; parasite systematics, including entomology, acarology, helminthology and protistology, and molecular analyses; molecular biology and biochemistry; immunology of parasitic diseases; host-parasite relationships; ecology and life history of parasites; epidemiology; therapeutics; new diagnostic tools.

All papers in Parasite are published in English. Manuscripts should have a broad interest and must not have been published or submitted elsewhere. No limit is imposed on the length of manuscripts.

Parasite (open-access) continues Parasite (print and online editions, 1994-2012) and Annales de Parasitologie Humaine et Comparée (1923-1993) and is the official journal of the Société Française de Parasitologie. 